\title{
Efecto del patólogo en la exactitud diagnóstica de la ecografía endobronquial lineal (EBUS-lineal) en la vida real: un estudio de cohorte
}

\author{
L. F. Giraldo-Cadavid', M. T. Perez-Warnisher ${ }^{2}$, I. Fernandez-Navamuel ${ }^{3}$, J. Alfayate ${ }^{3}$, A. Naya ${ }^{3}$, P. Carballosa ${ }^{3}$, A. Gimenez ${ }^{3}$, E. Cabezas ${ }^{3}$, F. \\ Martinez-Muñlz ${ }^{3}$, S. Alvarez ${ }^{3}$, J. Flandes ${ }^{3}$ \\ 1 Fundación Neumológica Colombiana; Universidad de La Sabana - Bogotá (Colombia), 2 Fundación Jiménez Diaz; Universidad de Navarra - Madrid \\ (España), 3 Fundación Jiménez Diaz - Madrid (España)
}

\section{INTRODUCCIÓN Y OBJETIVO}

La evidencia sobre el efecto del patólogo en la exactitud de la Ecobroncoscopia lineal (EBUS-lineal) es muy escasa. Nuestro objetivo fue evaluar el efecto del patólogo en la exactitud de la EBUS-lineal ajustando por posibles factores de confusión.

\section{MATERIALES Y MÉTODOS}

Estudio de cohorte, con pacientes reclutados secuencialmente. Todas las EBUS fueron realizadas por al menos un broncoscopista senior (experiencia> 100 EBUS), el patólogo que leyó las muestras tuvo una experiencia variada. El diagnóstico final se realizó mediante análisis histopatológico $(94 \%)$ o imágenes de seguimiento $(6 \%)$. Exploramos los factores que podrian afectar la exactitud diagnóstica, como el sexo, la edad, la indicación, el patólogo, el broncoscopista, el tamaño del ganglio, la estación y la disponibilidad de PET. Realizamos una regresión logística multivariada para ajustar por las variables de confusión.

\begin{tabular}{|c|c|}
\hline Sexo Hombre, n (\%) & $477(71,9)$ \\
\hline Edad, media (DE) & $63,7(12,9)$ \\
\hline \multicolumn{2}{|l|}{ Indicación de EBUS, n (\%) } \\
\hline Adenopatias (cáncer intratorácico) & $454(68,7)$ \\
\hline Adenopatias (cáncer extratorácico) & $65(9,8)$ \\
\hline Adenopatias inflamatorias & $51(7,7)$ \\
\hline Estadificación del cáncer & $46(7,0)$ \\
\hline Adenopatias infecciosas & $6(0,9)$ \\
\hline Revaloración histológica del cáncer & $2(0,3)$ \\
\hline Otra & $37(5,6)$ \\
\hline Tamaño de la adenopatía, mediana(RIQ) & $13,0(10-20)$ \\
\hline \multicolumn{2}{|l|}{ PET, $n$ (\%) } \\
\hline Negativa & $61(9,2)$ \\
\hline Positiva & $247(37,3)$ \\
\hline No se realizó & $355(53,5)$ \\
\hline \multicolumn{2}{|l|}{ Estadificación nodal, n (\%) } \\
\hline 7 & $195(29,4)$ \\
\hline AR & $165(24,9)$ \\
\hline $10 R$ & $103(15,5)$ \\
\hline 4L & $62(9,4)$ \\
\hline $10 \mathrm{c}$ & $47(7,1)$ \\
\hline $2 R$ & $24(3,6)$ \\
\hline $11 R$ & $18(2,7)$ \\
\hline $11 \mathrm{~L}$ & $16(2,4)$ \\
\hline $12 R$ & $7(1,1)$ \\
\hline $2 \mathrm{~L}$ & $5(0,8)$ \\
\hline 8 & $4(0,6)$ \\
\hline $12 \mathrm{~L}$ & $2(0,3)$ \\
\hline 5 & $2(0,3)$ \\
\hline 3 & $1(0,2)$ \\
\hline \multicolumn{2}{|l|}{ Complicaciones, $n$ (\%) } \\
\hline Ninguna & $662(99,8)$ \\
\hline Desaturación de oxigeno & $1(0,2)$ \\
\hline \multicolumn{2}{|l|}{ Modalidad anestesica, $n(\%)$} \\
\hline Sedación consciente & $660(99,5)$ \\
\hline Anestesia local & $3(0,5)$ \\
\hline Anestesia general & $0(0,0)$ \\
\hline
\end{tabular}

\section{RESULTADOS}

Se realizaron 663 EBUS. La edad media (+SD) fue de $63.7+12.9$ años, el $71.9 \%$ fueron del sexo masculino.

Las indicaciones más comunes fueron adenopatias mediastínicas en pacientes con sospecha de cáncer de pulmón $(68.7 \%)$, cáncer extratorácico $(9.8 \%)$ y adenopatías inflamatorias/infecciosas $(7.7 \%)$.

La mediana del tamaño de la adenopatía fue de $14 \mathrm{~mm}$ (IQR: $10 \mathrm{~mm}-20 \mathrm{~mm}$ ).

La exactitud global fue del $80.7 \%$. Las variables que se asociaron independientemente con una mayor exactitud de la EBUS fueron: estación $4 R(P=0.046)$ y la mayor experiencia del patólogo ( $P=0.02)$; las que se asociaron con menor exactitud fueron: diámetro de los ganglios en el eje corto $<1 \mathrm{~cm}(P=0,007)$, estaciones $11 R(P<0,01)$ y $10 R(P=0,03)$, y ciertos patólogos independientemente de su experiencia $(P<0,01)$.

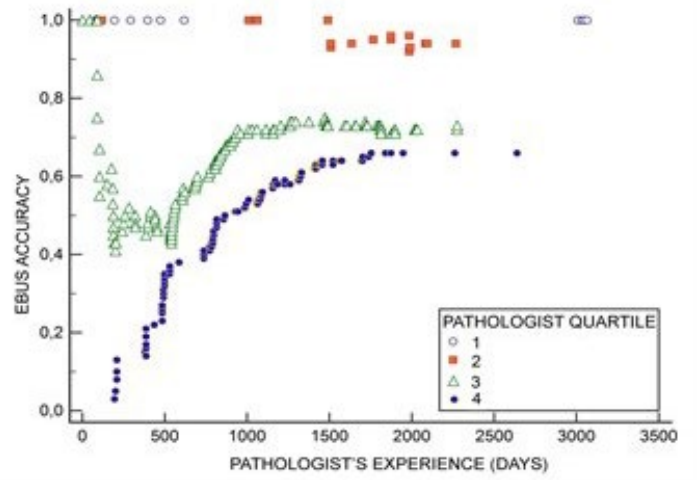

\section{CONCLUSIONES}

La estación nodal $4 \mathrm{R}$ y la mayor experiencia del patólogo se asociaron con una mayor exactitud de la EBUS. Los ganglios linfáticos pequeños, las estaciones nodales $11 R$ y $10 R$ y ciertos patólogos independientemente de su experiencia se asociaron con una menor exactitud de la EBUS. 